Southern Illinois University Edwardsville

SPARK

SIUE Faculty Research, Scholarship, and Creative Activity

Fall 10-3-2019

\title{
Fabrication and Thermal Characterization of Composite Cu-CNT Micropillars for Capillary-driven Phase-Change Cooling Devices
}

Gerardo Rojo

Siavash Ghanbari

Jeff Darabi

jdarabi@siue.edu

Follow this and additional works at: https://spark.siue.edu/siue_fac

Part of the Heat Transfer, Combustion Commons

\section{Recommended Citation}

G. Rojo, S. Ghanbari \& J. Darabi (2019) Fabrication and Thermal Characterization of Composite Cu-CNT Micropillars for Capillary-driven Phase-Change Cooling Devices, Nanoscale and Microscale

Thermophysical Engineering, DOI: 10.1080/15567265.2019.1675830

This Article is brought to you for free and open access by SPARK. It has been accepted for inclusion in SIUE Faculty Research, Scholarship, and Creative Activity by an authorized administrator of SPARK. For more information, please contact magrase@siue.edu. 
This is an Accepted Manuscript of an article published by Taylor \& Francis in Nanoscale and Microscale Thermophysical Engineering on 03 Oct 2019, available online: https://doi.org/10.1080/15567265.2019.1675830

\title{
Fabrication and Thermal Characterization of Composite $\mathrm{Cu}$-CNT Micropillars for Capillary-driven Phase-Change Cooling Devices
}

\author{
G. Rojo, S. Ghanbari, and J. Darabi ${ }^{1}$ \\ Department of Mechanical Engineering \\ Southern Illinois University Edwardsville \\ Edwardsville, Illinois 62026
}

\begin{abstract}
This paper presents the fabrication, testing, and modeling of an array of composite copper-carbon nanotubes $(\mathrm{Cu}-\mathrm{CNT})$ micropillars as a wick structure for potential application in passive phasechange cooling systems. This novel wick structure has a larger spacing at the base of the micropillars to provide a higher liquid permeability and mushroom-like structures on the top surface of the micropillars with a smaller spacing to provide a greater capillary pressure. The composite $\mathrm{Cu}-\mathrm{CNT}$ micropillars were fabricated by an electrochemical deposition method on a patterned copper template. Cauliflower-like nanostructures were then grown on the top surface of the micropillars using chronoamperometry technique to improve the capillary pressure and thermal performance of the wick structure. After successful fabrication of the micropillars, a series of tests were conducted to quantify the thermal performance of the wick structures. The results demonstrate superior thermal and corrosion performances for composite $\mathrm{Cu}-\mathrm{CNT}$ micropillars compared to those of copper micropillars. Additionally, a thermal resistance network analysis was conducted to model the thermal performance of the fabricated mushroom-shaped micropillar array. Model predictions were compared with the experimental results and good agreement was observed.
\end{abstract}

KEYWORDS: Micropillar wick structure, capillary pressure, thermal performance, heat pipe, vapor chamber, electronics cooling.

\section{Introduction}

Passive capillary-driven phase-change cooling systems such as heat pipes and vapor chambers have been used as effective heat spreaders in electronic cooling applications due to their compact size, light weight, high reliability, and favorable thermal performance [1-5]. In these devices, a working fluid undergoes a phase change by absorbing heat in the heat source (evaporator). The vapor then moves to the heat sink (condenser), where it condenses back into liquid and returns to the evaporator by the capillary action of a wick structure comprised of sintered copper particles, screen mesh, grooves, or their combination. The wicking structure in these devices provides the necessary capillary pressure to induce a flow capable of removing heat from the evaporator and rejecting it in the condenser. For normal operation of a heat pipe or a vapor chamber, the available capillary pressure head of the wick structure must be greater than the total pressure losses in the system.

\footnotetext{
${ }^{1}$ Author to whom correspondence should be addressed: Phone: (618) 650-3382, email: jdarabi@siue.edu
} 
This is an Accepted Manuscript of an article published by Taylor \& Francis in Nanoscale and Microscale Thermophysical Engineering on 03 Oct 2019, available online: https://doi.org/10.1080/15567265.2019.1675830

As the density of transistors in a chip continues to increase, improved cooling techniques are needed to efficiently remove heat from the next generation of high power density $3 \mathrm{D}$ chips and to maintain the chip temperature within an acceptable limit. Over the past decade, a number of researchers have proposed to use micro/nanopillars as a wick structure to improve the capillary pressure and thermal performance of vapor chambers and heat pipes. Plawsky et al. [6] provided a comprehensive review of micro- and nanostructures for phase-change heat transfer. Vadakkan et al. [7] proposed carbon nanotubes (CNTs) as a wick structure for vapor chambers and studied the wettability of CNT arrays using FC-72 as the working fluid. Ujereh et al. [8] performed pool boiling experiments on CNT-coated surfaces and reported increases of $6 \%$ and $45 \%$ in the critical heat flux for CNT-coated copper and silicon surfaces, respectively. Zhou et al. [9] proposed CNT nanowicks as a miniature liquid delivery system for potential applications in microfluidic chemical analysis devices. Cai and Chen [10] fabricated and tested a CNT biwick structure composed of $250 \mu \mathrm{m}$ tall and $100 \mu \mathrm{m}$ wide nanoporous CNT clusters, separated by $50 \mu \mathrm{m}$ wide passages and reported a maximum heat flux of $600 \mathrm{~W} / \mathrm{cm}^{2}$ over a $2 \mathrm{~mm} \times 2 \mathrm{~mm}$ heating area. Weibel et al. [11] incorporated CNT coatings into porous microstructures to enhance boiling heat transfer and reported up to $72 \%$ reduction in the wall superheat. Nam et al. [12] fabricated and characterized the capillary performance of arrays of copper microposts with diameters of $30-100 \mu \mathrm{m}$, pitches of $62.5-115 \mu \mathrm{m}$, and heights of $50-120 \mu \mathrm{m}$. Their results showed that the capillary performance of micropost arrays increased with increasing the post height while it decreased with increasing the post diameter and pitch. Ding et al. [13] developed a titanium-based flat heat pipe by etching a pillar array with a diameter of $5 \mu \mathrm{m}$, a pitch of $10 \mu \mathrm{m}$, and a height of $50 \mu \mathrm{m}$ in a titanium substrate for thermal ground plane applications. Hairlike nanostructured titania was grown on the pillar surfaces to increase the surface wettability. The wetting velocities of titanium pillars coated with nanostructured titania was found to increase by as much as $160 \%$ compared to uncoated titanium pillars. Chiua et al. [14] examined larger micropillars with a height of $500 \mu \mathrm{m}$ and reported an increase in the thermal resistance of the micropillar array as the spacing between the micropillars increased. Ranjan et al. [15-17] analyzed the use of CNT nanostructures to enhance the capillary transport performance of nanostructured wicks in heat-spreading applications. They investigated the thermal and capillary performance of several wick configurations with different shapes, including spherical, cylindrical, square, and hexagonal arrangements. The spherical array was found to provide a higher capillary pressure than the cylindrical array. In addition, hexagonal arrangement offered a better performance compared to that of the square arrangement. Weibel et al. [18] numerically simulated the thermal performance of a vapor chamber with a nanostructured CNT array as the wicking material in the evaporator section. They reported a significant reduction in thermal resistance by using an integrated sintered and nanostructured wick enhanced with CNT nanostructures. Adera et al. [19] investigated the use of a silicon micropillar array as a wick structure to improve the thermal performance of wicking structures in heat pipes and vapor chambers. The wick structure comprised of silicon micropillar arrays with a pillar diameter of 5-

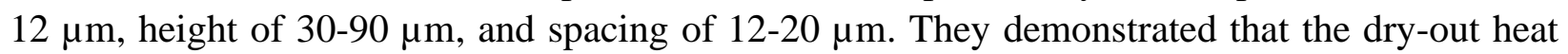
flux increased with increasing micropillar height while there were an optimum pillar diameter and spacing at which the dryout heat flux was maximum. Zhu et al. [20] developed a numerical model and predicted the meniscus curvature and dryout heat flux for various micropillar wick structures. Very recently, Hanks et al. [21] designed, fabricated, and experimentally characterized a 
nanoporous silicon membrane and bonded it to a high permeability silicon microchannel array to create a biporous wick for thermal management of ultra-high power density electronics. They demonstrated a maximum heat flux of $665 \mathrm{~W} / \mathrm{cm}^{2}$ over $0.172 \mathrm{~mm} \times 10 \mathrm{~mm}$ heating area at a wall superheat of $28.5 \mathrm{~K}$ using pentane as the working fluid.

While nanopillars could provide a higher capillary pressure and larger thin-film regions, their permeability is extremely low. The low permeability causes a significant increase in the liquid pressure drop, which in turn results in a lower system performance. On the other hand, micropillars have a higher permeability than nanopillars, thus offering a greater ease of flow, but they suffer from a lower capillary pressure. Thus, a proper wick design presents a challenge due to a tradeoff between these two competing effects. In an attempt to provide a high capillary pressure while maintaining a high liquid permeability, alternative designs must be considered. In this study, mushroom-like composite $\mathrm{Cu}-\mathrm{CNT}$ micropillars were fabricated as a wick structure for potential use in capillary-driven heat pipes and vapor chambers. Figure 1 illustrates a cutaway view of a vapor chamber with the proposed semispherical mushroom-like micropillars. This wick structure has a larger spacing at the base of the micropillars to provide a higher liquid permeability and a smaller spacing between the mushroom heads to provide a higher capillary pressure, which are two important features in these types of applications. To fabricate the wick structure, composite $\mathrm{Cu}-\mathrm{CNT}$ micropillars were first grown on a patterned copper template by an electrochemical deposition method. Next, cauliflower-like nanostructures were grown on the top surface of the micropillars using chronoamperometry technique to improve the capillary pressure and thermal performance of the wick structure. After successful fabrication of the micropillars, the thermal performance of the wick structure was experimentally investigated. Additionally, it has been reported in literature that copper microstructure wicks are susceptible to corrosion. Thus, to study the corrosion behavior of the fabricated micropillars, an electrochemical impedance spectroscopy method was used to determine the effect of working fluid on the corrosion of the wick structures. Furthermore, a numerical simulation was performed to study the thermal characteristics of these mushroom-shaped micropillars.

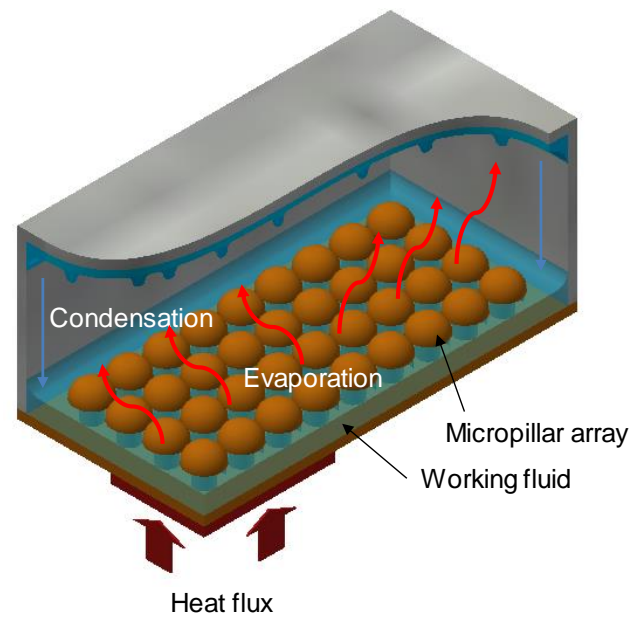

Figure 1 A schematic illustration of a vapor chamber with mushroom-shaped micropillars 


\section{Fabrication of Composite Cu-CNT Micropillars}

In this work, composite $\mathrm{Cu}-\mathrm{CNT}$ micropillars were fabricated on a copper substrate as a wick structure for potential use in capillary-driven heat pipes and vapor chambers. Copper has excellent thermal and electrical conductivities and is commonly used as a heat spreader in electronic cooling applications. However, copper has a high coefficient of thermal expansion (CTE) and its corrosion resistance is relatively poor. On the other hand, CNTs possess a low coefficient of thermal expansion, a very high thermal conductivity, and a high corrosion resistance [22]. Thus, the reliability of electronic devices can be improved if materials with low coefficient of thermal expansion, high thermal conductivity, and better corrosion resistance such as composite $\mathrm{Cu}-\mathrm{CNT}$ structures are used. Figure 2 illustrates a simplified process flow to fabricate composite $\mathrm{Cu}-\mathrm{CNT}$ mushroom-like micropillars. One of the crucial steps in the fabrication of a micropillar array is making a template. The photolithography process is the standard technique for pattern transfer in microfabrication. However, this method is very expensive and requires cleanroom environment and sophisticated equipment. In this study, a polystyrene mesh net with an opening size of $50 \mu \mathrm{m}$ and a thickness of $112 \mu \mathrm{m}$ was used as a micropillar array template. While these dimensions may not be the optimum geometry, this was the smallest mesh net that was commercially available. This method was found to be a very rapid and inexpensive way to make the micropillar pattern and was suitable to demonstrate the proof of concept. First, a copper substrate was polished using waterproof sandpapers with grit sizes of 600,800 and 1000 . Next, the polyester mesh template was bonded to the polished copper plate by applying heat and pressure. The template was sandwiched between the polished substrate and a backing plate of a similar size, and a uniform pressure was then applied on the template using a clamp. To prevent bonding of the template to the backing plate, a plastic sheet was placed between them. The entire fixture was placed in an oven for 1 hour at $140{ }^{\circ} \mathrm{C}$. After heat treatment, the specimen was removed from the oven and allowed to cool at room temperature. The clamp and the backing copper plate were then removed. 
This is an Accepted Manuscript of an article published by Taylor \& Francis in Nanoscale and Microscale Thermophysical Engineering on 03 Oct 2019, available online: https://doi.org/10.1080/15567265.2019.1675830

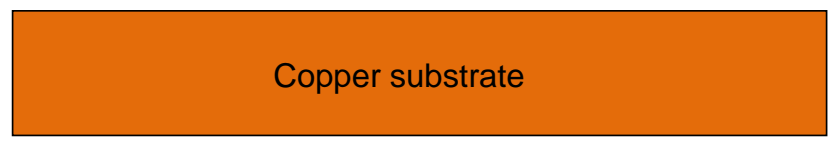

Polish a copper substrate

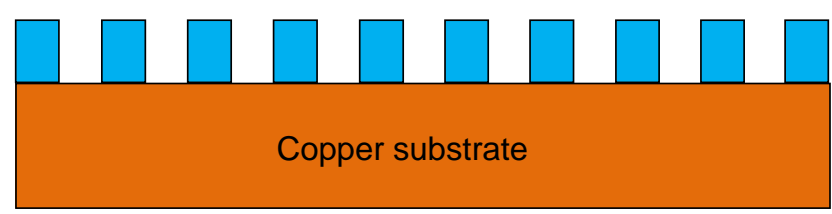

Cut and bond a piece of polyester mesh template to the copper substrate

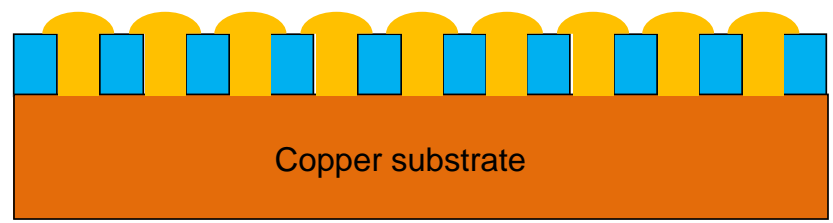

Grow mushroom-shaped Cu-CNT micropilllars using electrochemical deposition

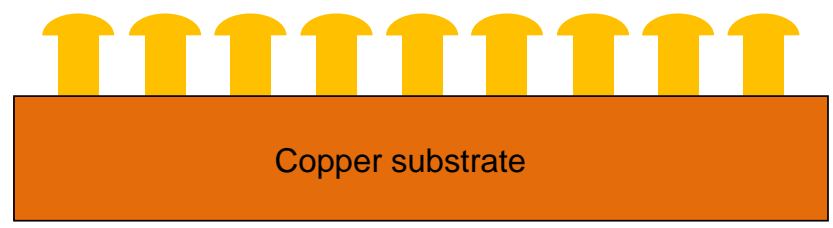

Etch polyester mesh template using a saturated $\mathrm{NaOH}$ solution

Figure 2 Process flow for micropillar array fabrication

Then, composite $\mathrm{Cu}-\mathrm{CNT}$ micropillars were grown using electrochemical deposition in an electrochemical cell. The electrochemical deposition is a relatively simple and inexpensive process and does not require any sophisticated equipment. The composition of the electrodeposition bath was $65 \mathrm{~g} / \mathrm{L} 4 \mathrm{CuSO}_{4} .5 \mathrm{H}_{2} \mathrm{O}, 70 \mathrm{~g} / \mathrm{L} \mathrm{H}_{2} \mathrm{SO}_{4}$ and $75 \mathrm{ppm}$ chloride ion $\left(\mathrm{Cl}^{-}\right)$. All chemicals were of analytical grade and the deionized water was of ultra-high purity. A polished copper plate (anode) was positioned vertically parallel to the specimen (cathode). The gap between the anode and cathode was $3 \mathrm{~cm}$. During the electrodeposition process, the solution was stirred by a magnetic stirrer to keep the particles in suspension. Multi-walled carbon nanotubes (MWCNTs) with a diameter of less than $10 \mathrm{~nm}$ and a length of 1-2 $\mu \mathrm{m}$ were purchased from Sigma-Aldrich Corporation (St. Louis, MO). To prevent agglomeration of CNTs, CNT particles were dispersed in a mixture of $20 \mathrm{~mL}$ of water and $2 \mathrm{~g} / \mathrm{L} \mathrm{SDS}$ at a concentration of $3 \mathrm{~g} / \mathrm{L}$. The solution was then subjected to ultrasonic vibration for 2 hours. After sonication, the CNT solution was added to the copper electrodeposition solution to grow $\mathrm{Cu}-\mathrm{CNT}$ micropillars. CNT particles are intrinsically inert. However, when surfactants such as sodium dodecyl sulfate (SDS) is added, the surfactant is adsorbed on the surface of the CNT particles. Since the SDS surfactant has a negative charge, negatively charged $\mathrm{CNT}$ particles are formed. $\mathrm{Cu}^{2+}$ ions in the electrolyte solution are then attracted to the negatively charged CNT particles (due to adsorption of SDS on CNT surface) and positively charged $\mathrm{Cu}^{2+}-\mathrm{CNT}$ complexes are formed. When an external electric field is applied, these $\mathrm{Cu}^{2+}$ - CNT complexes migrate towards the cathode, where they are discharged and deposited 
on the cathode surface to obtain composite $\mathrm{Cu}-\mathrm{CNT}$ structures. The volume fraction of $\mathrm{CNTs}$ in the micropillars was determined using Clemex image analyzer software and found to be approximately $20 \%$ at a current density of approximately $7 \mathrm{~A} / \mathrm{dm}^{2}$. After electrodeposition of composite $\mathrm{Cu}-\mathrm{CNT}$ micropillars, cauliflower-like nanostructures were grown on the surface of the micropillars using a chronoamperometry method to further improve the capillary pressure and thermal performance of the micropillars. Copper chloride was used as a copper source, and cetyl trimethyl ammonium bromide (CTAB), SDS, and porpoly vinyl pyrrolidone (PVP) were used as the shape-controllers to adjust the morphologies of metal copper hierarchical structures. A potentiostate was used to control the deposition parameters such as voltage and current density and surfactants were added to the electrodeposition bath to control and obtain the desired shape. As a final step, the mesh template was etched using a saturated $\mathrm{NaOH}$ solution at $140{ }^{\circ} \mathrm{C}$ for four hours. Once the template was dissolved, the specimen was cleaned by a $3 \%$ sulfuric acid solution at room temperature for 30 seconds.

A representative image of fabricated $\mathrm{Cu}-\mathrm{CNT}$ micropillars is shown in Fig. 3. The side wall of the micropillars was observed to be relatively smooth. However, fabricating uniform micropillars using the mesh template was found to be challenging. The polyester mesh template was observed to deform due to the applied heat and pressure during its attachment to the copper substrate. As a result, this method produced oval-shaped micropillars. The average diameter and of height of the micropillars were approximately $50 \mu \mathrm{m}$ and $114 \mu \mathrm{m}$, respectively. The average center to center distance between the bases of the micropillars was approximately $100 \mu \mathrm{m}$. The gap between the mushroom heads on top of the pillars can be controlled by adjusting the electroplating time and was found to be approximately $4-5 \mu \mathrm{m}$. 


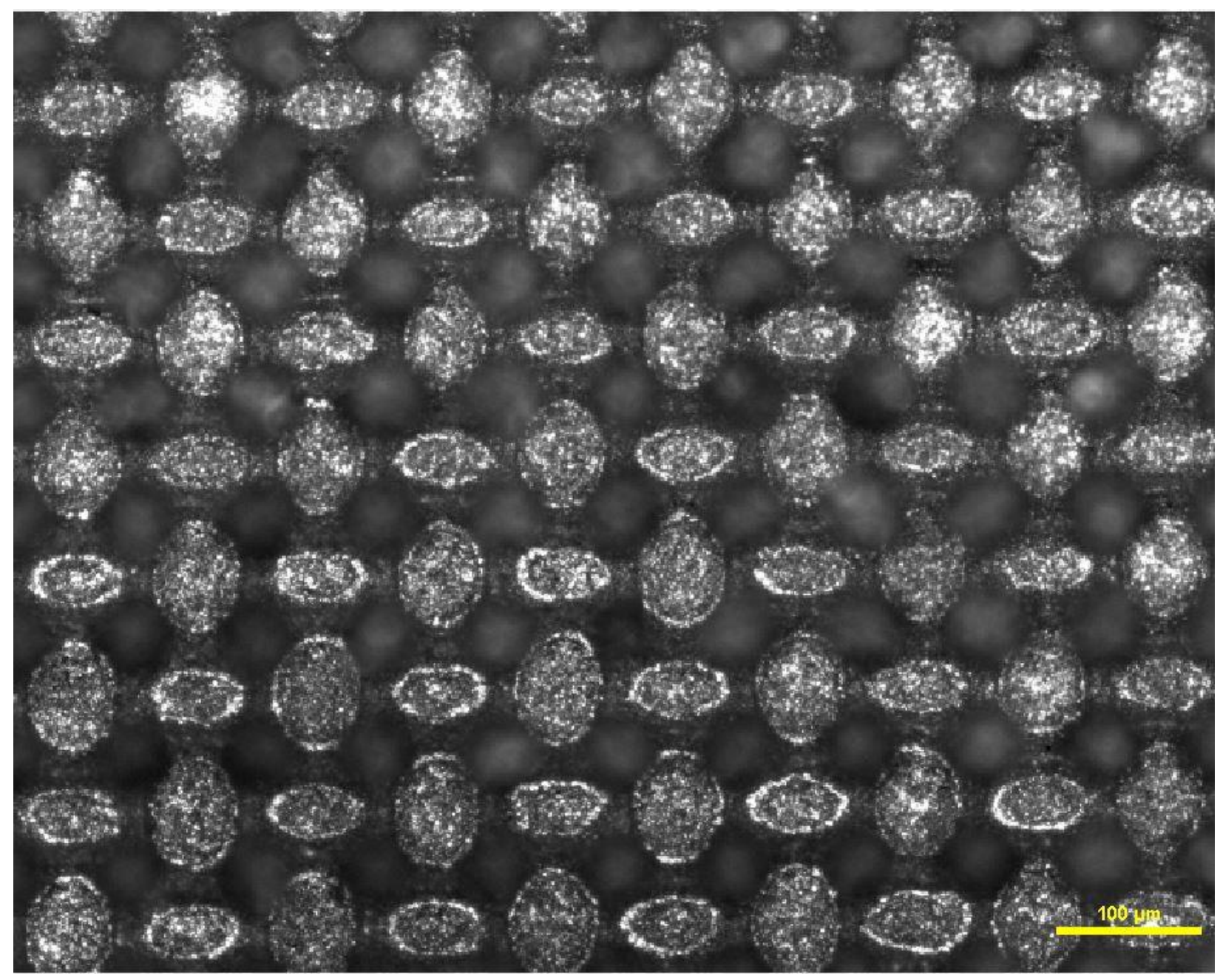

Figure 3 A microscope image of fabricated micropillars by electrodeposition method using a polyester mesh template. Oval-shaped structures are produced due to the deformation of mesh template under applied heat and pressure.

\section{Experimental Characterization}

After successful fabrication of copper and $\mathrm{Cu}-\mathrm{CNT}$ composite micropillars on a polished copper substrate, thermal characterization tests were performed to quantify and compare the performance of the micropillar wick structures. These micropillars have a larger spacing at the base of the micropillars to provide a higher liquid permeability and a smaller spacing between the mushroom heads to provide a larger capillary pressure which are two important features to improve the thermal performance of passive phase-change cooling systems.

\subsection{Experimental setup and instrumentation}

Figure 4 shows a schematic illustration and a photograph of an experimental setup used to measure the thermal performance of the micropillars. The setup consists of a vacuum sealed chamber, a test fixture, a refrigerated bath/circulator, a data acquisition system (DAS), and two DC power supplies. The vacuum chamber is equipped with view ports, power and thermocouple feedthroughs, a pressure transducer, and charging and discharging valves. A liquid cooled trap, mounted on the top plate was used to remove the heat generated in the test chamber and condense 
the vapor. A refrigerated bath/circulator was used to control and supply chilled water to the cooled trap. A data acquisition system was used to monitor, control, and acquire data. A power feedthrough was used to make electrical connections to the test fixture heater and a thermocouple feedthrough was used to make connections to T-type thermocouple wires inside the vacuum chamber. To simulate a chip in operation, a thin film Polyimide heater (Minco, Minneapolis, MN) with a size of $5 \mathrm{~mm} \times 5 \mathrm{~mm}$ was attached to the back side of the micropillars substrate. A variable DC power supply was used to provide the electric power to the heater. Four small holes were drilled at the center of each edge of the substrate and four T-type thermocouples were inserted in the holes to measure the substrate temperature. A thermal conducting paste (Omega Engineering) was applied to fill the holes. Square substrates were $25.4 \mathrm{~mm}$ on each side and $3.2 \mathrm{~mm}$ thick. The overall size of micropillar array were $14 \mathrm{~mm} \times 14 \mathrm{~mm}$. The substrate was then placed between two Teflon blocks for thermal insulation purposes and secured by screws. A square opening was cut at the center of the front Teflon block to expose the micropillars to the working fluid. A small Teflon block with a slot was used to position the test fixture vertically on the bottom plate inside the chamber. An Agilent data acquisition system (34970A) was used to monitor and record readings from thermocouples, pressure transducer, and power to the heater. For each run, all the data were recorded every 10 seconds for a period of 4400 seconds.

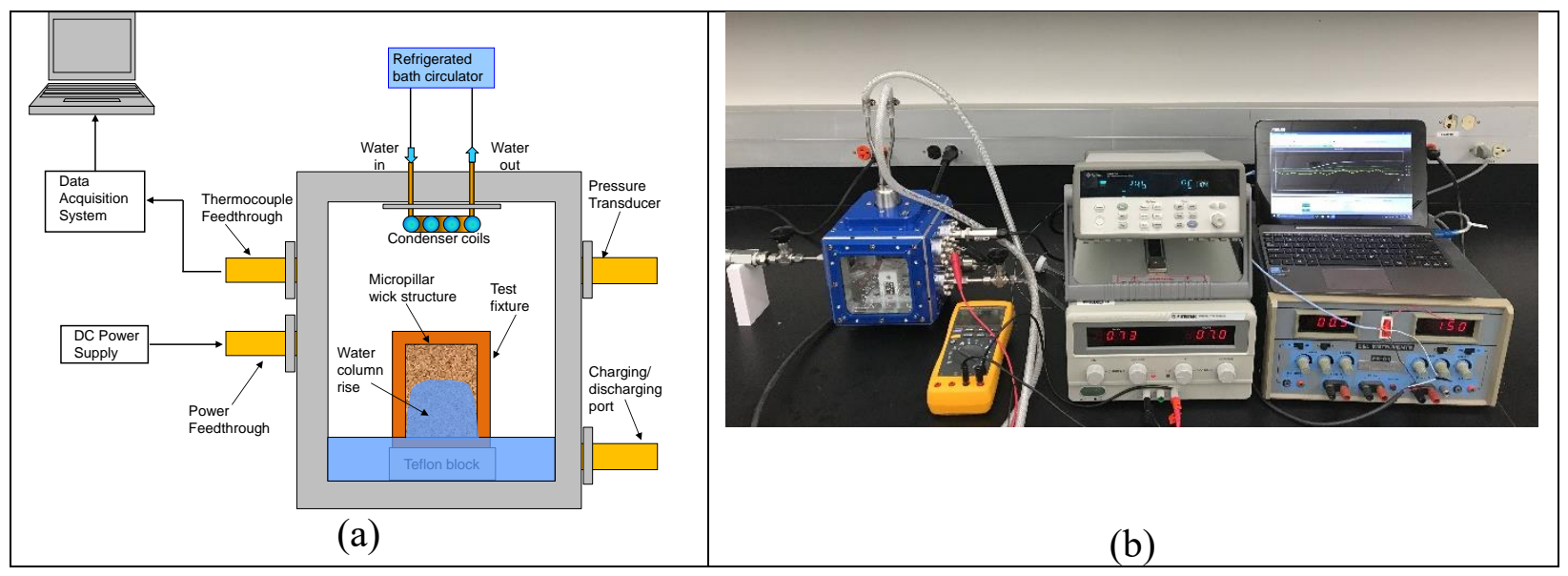

Figure 4 (a) A schematic and (b) a photograph of the test setup for thermal characterization tests

\subsection{Experimental procedure}

Before each test, the test fixture was cleaned and the chamber was filled with deionized and degassed water until a small portion of the micropillars array was submerged in the liquid. Next, the power to the heater was turned on and the substrate temperature was monitored. The presence of micropillars on the substrate surface induces capillary forces, causing the water level to rise through the micropillars. The heat flux to the heater was varied from 10 to $80 \mathrm{~W} / \mathrm{cm}^{2}$. At any given heat flux, the substrate temperature was monitored until a steady state was reached. The data were recorded using an Agilent data acquisition system. The power to the heater was then incremented to the next level and this process was repeated. In each experiment, the measured variables consisted of temperature, voltage and, current. All tests were carried out at room temperature to minimize heat losses or gains to the test chamber. The saturation temperature inside the chamber was maintained at $24{ }^{\circ} \mathrm{C}$ and it was kept constant during all tests. Each test was repeated three times to ensure repeatability. 
This is an Accepted Manuscript of an article published by Taylor \& Francis in Nanoscale and Microscale Thermophysical Engineering on 03 Oct 2019, available online: https://doi.org/10.1080/15567265.2019.1675830

\subsection{Data reduction}

The electrical power to the heater was calculated from the measured voltage and current as follows:

$$
P=V I
$$

where $\mathrm{V}$ is the voltage and I is the electrical current. The heat flux generated by the heater was then calculated by dividing the net input power to the heater by the nominal area of the heater, and accounting for small heat losses to the surroundings,

$$
q^{\prime \prime}=\frac{q}{A}
$$

where A represent the heater surface area. The wall superheat was calculated from the temperature measurements using

$$
\Delta \mathrm{T}=T_{\text {sub }}-T_{\text {sat }}
$$

where $T_{\text {sub }}$ is the average temperature of the substrate and $T_{\text {sat }}$ is the saturation temperature inside the chamber. A one dimensional (1-D) heat transfer analysis was performed to determine the heat losses from the backside of the test fixture. Heat transfer occurs from the substrate by conduction through the Teflon insulation material and by convection from the backside of the Teflon block to the vapor. Since the substrate temperature $\left(\mathrm{T}_{\text {sub }}\right)$ and the saturation temperature $\left(\mathrm{T}_{\mathrm{sat}}\right)$ inside the chamber were experimentally measured, heat losses can be estimated from the 1-D thermal resistance analysis given by

$$
\begin{gathered}
R_{\text {loss }}=\frac{1}{A}\left(\frac{L_{\text {ins }}}{k_{\text {ins }}}+\frac{1}{h}\right) \\
Q_{\text {loss }}=\frac{T_{\text {sub }}-T_{\text {sat }}}{R_{\text {loss }}}
\end{gathered}
$$

where $\mathrm{k}_{\mathrm{ins}}$ and $\mathrm{L}_{\mathrm{ins}}$ are the thermal conductivity and thickness of the insulation material, $\mathrm{h}$ is the convection heat transfer of the vapor, and $\mathrm{A}$ is the heat transfer area. The average free convection heat transfer coefficient for the vapor was estimated to be approximately $25 \mathrm{~W} / \mathrm{m}^{2} . \mathrm{K}$ using a correlation that has been recommended by Churchill and Chu for a vertical plate, which can be found in any basic heat transfer textbook. The rate of heat losses calculated using the above procedure was found to be approximately $0.58 \%$ of the total power to the heater. The heat loss was then subtracted from the total power input to the heater to obtain the net heat transfer rate from the front surface via evaporation.

The overall thermal resistance is calculated from

$$
R=\frac{\Delta T}{q}
$$

where $\Delta \mathrm{T}$ is the difference between the substrate and saturation temperatures and $\mathrm{q}$ is the net heat transfer rate.

\subsection{Experimental uncertainty analysis}


The propagation of error method proposed by Kline and McClintock [23] was used to calculate the experimental uncertainties in power, heat flux, and thermal resistance. Propagation of error takes into account all individual measurements that could affect the dependent variable and is given by:

$$
U_{R}= \pm\left[\left(\frac{x_{1}}{R} \frac{\partial R}{\partial x_{1}} u_{1}\right)^{2}+\left(\frac{x_{2}}{R} \frac{\partial R}{\partial x_{1}} u_{2}\right)^{2}+\cdots+\left(\frac{x_{n}}{R} \frac{\partial R}{\partial x_{n}} u_{n}\right)^{2}\right]^{\frac{1}{2}}
$$

where $U_{R}$ is the associated error of the dependent variable $\mathrm{R}$, and $x_{1}, x_{2}, \ldots x_{n}$ are the measured variables affecting $R$, and $u_{1}, u_{2}, \ldots u_{3}$ are the relative uncertainties of the measured variables. In this study, all thermocouples were calibrated in a high precision temperature calibration bath with an accuracy of $\pm 0.1{ }^{\circ} \mathrm{C}$. For the range of voltage and current used in this study, the accuracy of the electric current and voltage was $\pm 0.56 \%$. The relative uncertainty in heat flux is the same as that of power since the nominal area of the heater was used in propagation of error calculations, which turned out to be $\pm 0.8 \%$. The relative uncertainties for the thermal resistance as a function of heat flux are summarized in Table 1. The results show that the experimental uncertainty decreases with increasing the heat flux. This is due to the fact that the wall superheat is smaller at lower heat fluxes, resulting in a higher uncertainty in the thermal resistance.

Table 1: Experimental uncertainty analysis results

\begin{tabular}{|c|c|}
\hline Heat flux $\left(\mathbf{W} / \mathbf{c m}^{2}\right)$ & Percent Error \\
\hline 6.5 & $\pm 4.22 \%$ \\
\hline 14.6 & $\pm 2.35 \%$ \\
\hline 25.6 & $\pm 1.50 \%$ \\
\hline 40.0 & $\pm 1.15 \%$ \\
\hline 57.1 & $\pm 1.04 \%$ \\
\hline 78.0 & $\pm 0.89 \%$ \\
\hline
\end{tabular}

\section{Thermal Resistance Network Modeling}

A thermal resistance network analysis was performed to predict and determine the thermal performance of the micropillars. The heat is conducted from the heater into the substrate, where most of it is then conducted to solid portion of the micropillar array. The heat is finally dissipated via evaporation from the thin-film region of micropillar structures. The overall thermal resistance for the micropillar array is composed of three main thermal resistances given by the following equation

$$
R=R_{s p}+R_{m p}+R_{T F}
$$

where $R_{s p}$ is the spreading resistance between the heat source and the substrate, $R_{m p}$ is the resistance associated with the micropillar control volume, and $R_{T F}$ is the thin-film thermal resistance. To compute these resistances, the principal node temperatures were obtained from a CFD analysis described in the next section. The thermal spreading resistance occurs as heat flows 
from the heater into the copper substrate because the cross-sectional area of the heater is smaller than that of the copper substrate. The spreading resistance can be calculated as follows

$$
R_{s p}=\frac{T_{h}-T_{s}}{q}
$$

where $\mathrm{q}, T_{h}$, and $T_{s}$ are the rate of heat transfer, heat source surface temperature, and substrate temperature, respectively. The thermal resistance of the micropillar control volume was calculated from data obtained from the CFD Analysis. Since the convective heat transfer coefficient varies in the thin-film region, a multi-segment approach was used, where each segment was treated as a separate resistance. The thermal resistance in the thin-film region was calculated using the following relationship

$$
R_{T F, i}=\frac{1}{h_{i} A_{i}}
$$

where $h_{i}$ and $A_{i}$ are the heat transfer coefficient and surface area in segment, i, of the thin-film region. The total thermal resistance in the thin-film region was then calculated using the following equation

$$
\frac{1}{R_{T F}}=\sum_{i=1}^{n} \frac{1}{R_{T F, i}}
$$

\subsection{Governing equations and boundary conditions}

A 3-D thermal analysis of the micropillars was performed in ANSYS Fluent. ANSYS Fluent solves conservation equations for mass, momentum, and energy equations. In the absence of a source term, the energy equation at steady state condition reduces to:

$$
\nabla \cdot(\vec{v}(\rho E+p))=\nabla \cdot(k(\nabla T))
$$

A 3D model of the computational domain is shown in Fig. 5. The model was constructed in Autodesk Inventor and then imported and meshed in ANSYS Fluent. Since the micropillar geometry exhibits a repetitive pattern, to save computational time, only one unit cell of the micropillar array was modeled (refer to dashed line in Fig. 5). The micropillar geometry was modeled as a cylindrical pillar with a semi-spherical structure on top. The region between micropillars is filled with water. A constant heat flux boundary condition was applied to the backside of the substrate. Convective heat transfer boundary conditions were specified at the thinfilm evaporation region, water interface, and the dry portion of the micropillar head. Symmetry boundary conditions were applied to all four sides of the computational domain. 

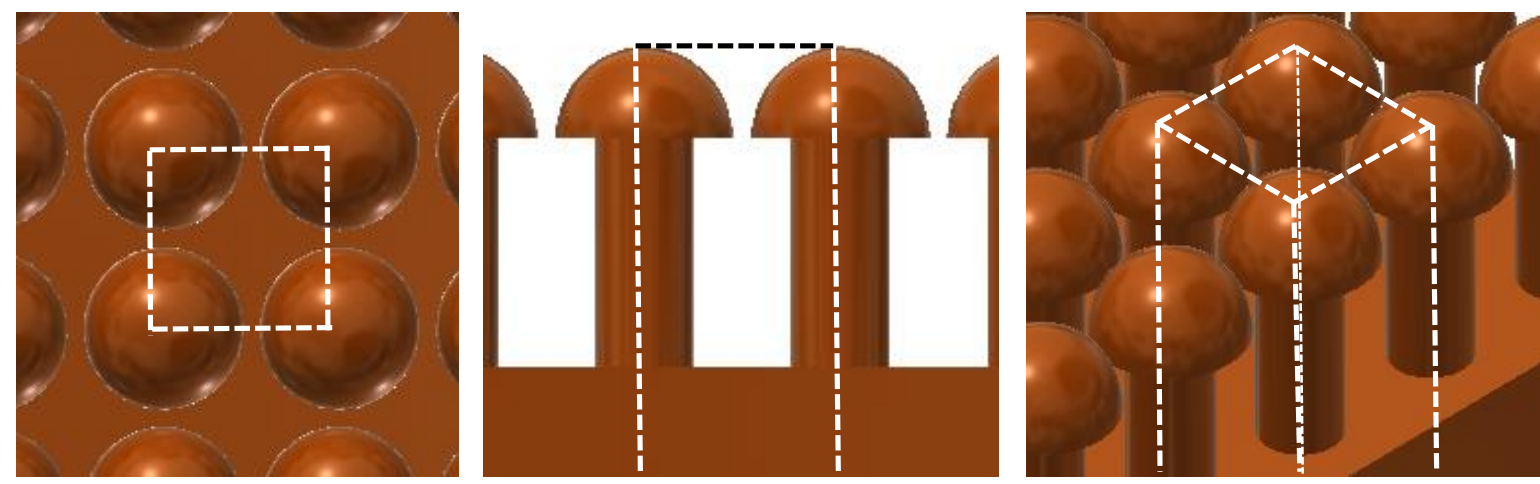

Figure 5 A schematic of the model geometry showing the computation domain used in the thermal analysis model

The semi-spherical portion of the micropillar structure is subjected to a varying heat transfer coefficient. The portion of the micropillar head that is covered by the thin-film region, is characterized by a high evaporation heat transfer coefficient while the remaining part of the micropillar head is governed by free convection. The heat transfer coefficient in the thin-film region was prescribed based on a model reported by park et al. [24-25]. The meniscus curvature was assumed to be the same for all micropillars regardless of their positions with respect to the heat source. The meniscus curvature was set based on a model developed by Zhu et al. [20]. Park et al. [25] investigated the thickness and thermal behavior of water in the thin-film region at various heat fluxes. Data from Park et al. [25] was used to curve fit and obtain a function which best described the convective heat transfer coefficient in the thin-film region. The curve fitted polynomial function is given by the following equation, where $y$ is the length of the thin-film region and ranges from 0 to $8 \mu \mathrm{m}$.

$$
\begin{gathered}
h(y)=60.748 y^{6}-1378.3 y^{5}+10736 y^{4}-33875 y^{3}+51384 y^{2} \\
-12293 y+27887
\end{gathered}
$$

Since the convective heat transfer coefficient in the thin-film region varies significantly, the thinfilm region was divided into ten equal segments. The average heat transfer coefficient for each segment was calculated and applied as a boundary condition to the corresponding segment using the following equation:

$$
\bar{h}_{i}=\frac{1}{b_{i}-a_{i}} \int_{a_{i}}^{b_{i}} h(y) d y
$$

where $a_{i}$ and $b_{i}$ are the starting and end lengths of the thin film region in segment $\mathrm{i}$. All simulations were performed at a steady-state condition and materials properties were obtained from ANSYS Fluent library. However, as discussed in the thermal characterization section, the thermal conductivity of $\mathrm{Cu}-\mathrm{CNT}$ micropillar structure was estimated to be $704.5 \mathrm{~W} / \mathrm{m} . \mathrm{K}$, and this value was used in the simulations.

\subsection{Grid independence study}

Prior to performing the simulations, a grid independence study was carried out to ensure that the results were sufficiently grid-independent. The optimum node element size was found to be 0.2 $\mu \mathrm{m}$ in the evaporation region and $2 \mu \mathrm{m}$ in the remaining domain. The mesh size was significantly 
smaller at the thin-film region because most of the heat transfer occurs in this region. Figure 6 shows an enlarged view of the mesh in the thin-film evaporation region on the semispherical portion of the micropillars. The inset shows a zoomed-in view of the thin-film region. Figure 7 shows the changes in temperature difference between the backside of the substrate and thin-film evaporation region as a function of the number of mesh elements. The results indicate that when the number of mesh elements was higher than approximately 1,000,000, the temperature difference remained nearly unchanged. Hence, the number of elements was considered to be adequate and the rest of simulations was run with $1,800,000$ elements.

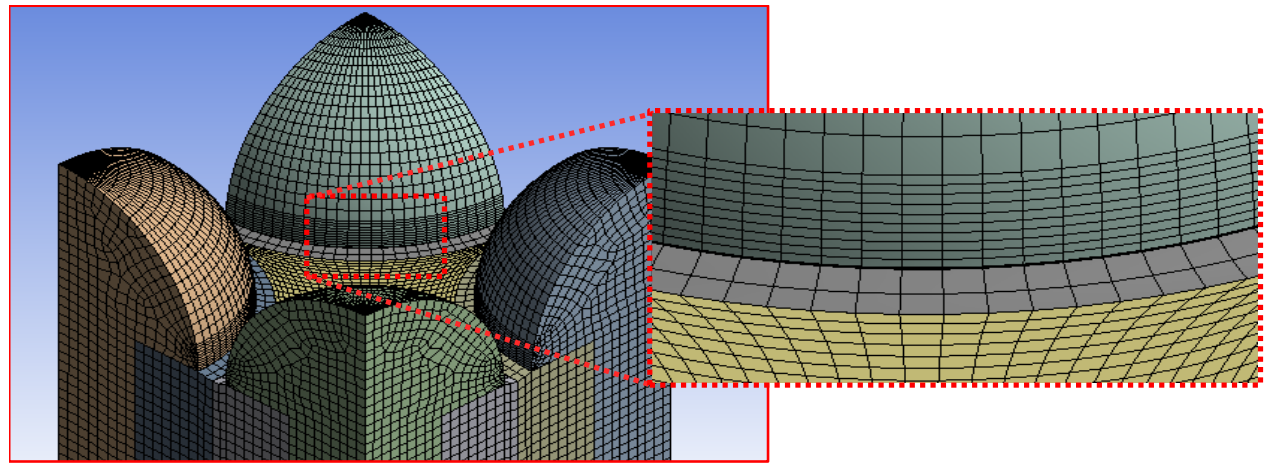

Figure 6 An enlarged view of the mesh in the thin-film evaporation region

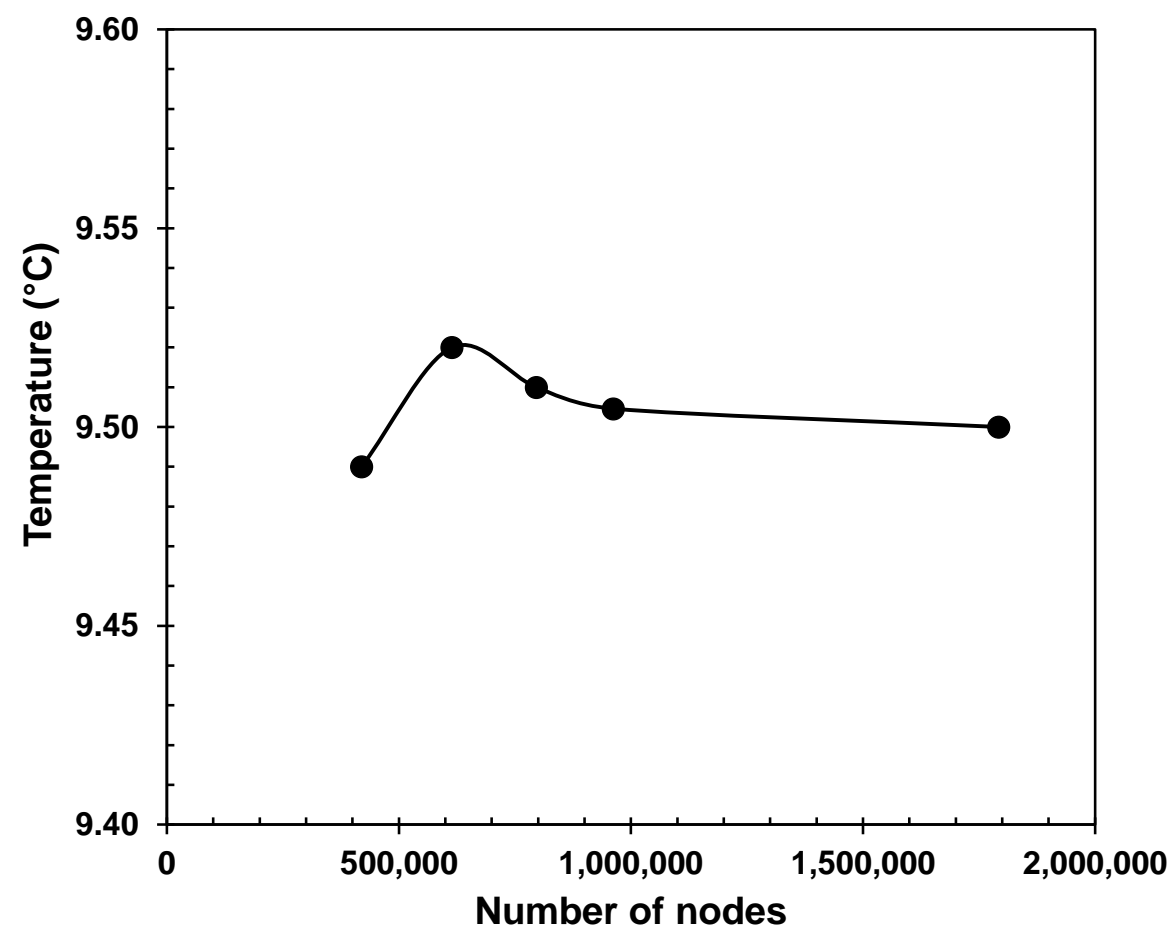

Figure 7 Grid independence study 


\section{Results and Discussion}

\subsection{Modeling results}

Figures 8 and 9 shows representative temperature and heat flux distributions in the micropillar region. The results indicate that the maximum temperature occurs in the central region at the base of micropillars which is in contact with water. This behavior can be explained by the fact that the thermal conductivity of water is significantly lower than that of $\mathrm{Cu}-\mathrm{CNT}$ micropillars, resulting in a higher temperature. The results also show that the lowest temperature is experienced in the thinfilm region due to evaporation at the liquid-vapor interface. The thin-film region experiences heat fluxes as high as $7.1 \times 10^{6} \mathrm{~W} / \mathrm{m}^{2}$. As expected, the heat flux is highest at the upper segment of the thin-film region due to its lowest thin film thickness and highest heat transfer coefficient and gradually decreases in the lower segments because the film thickness increases and the convective heat transfer coefficient decreases.

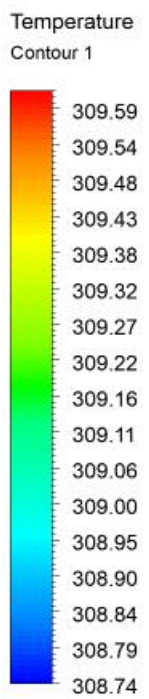

$[\mathrm{K}]$
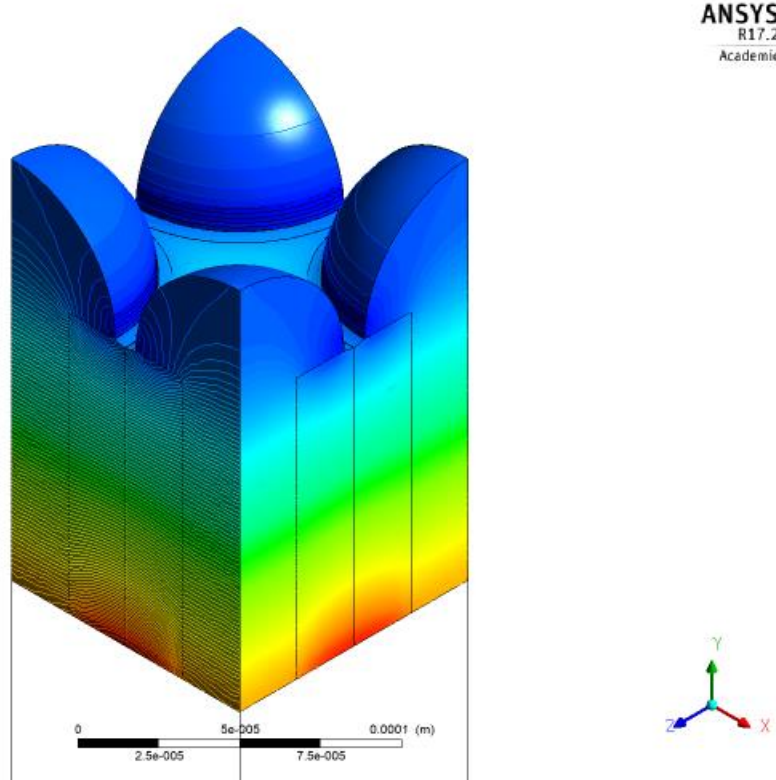

Figure 8 Representative temperature distribution in the micropillar region 


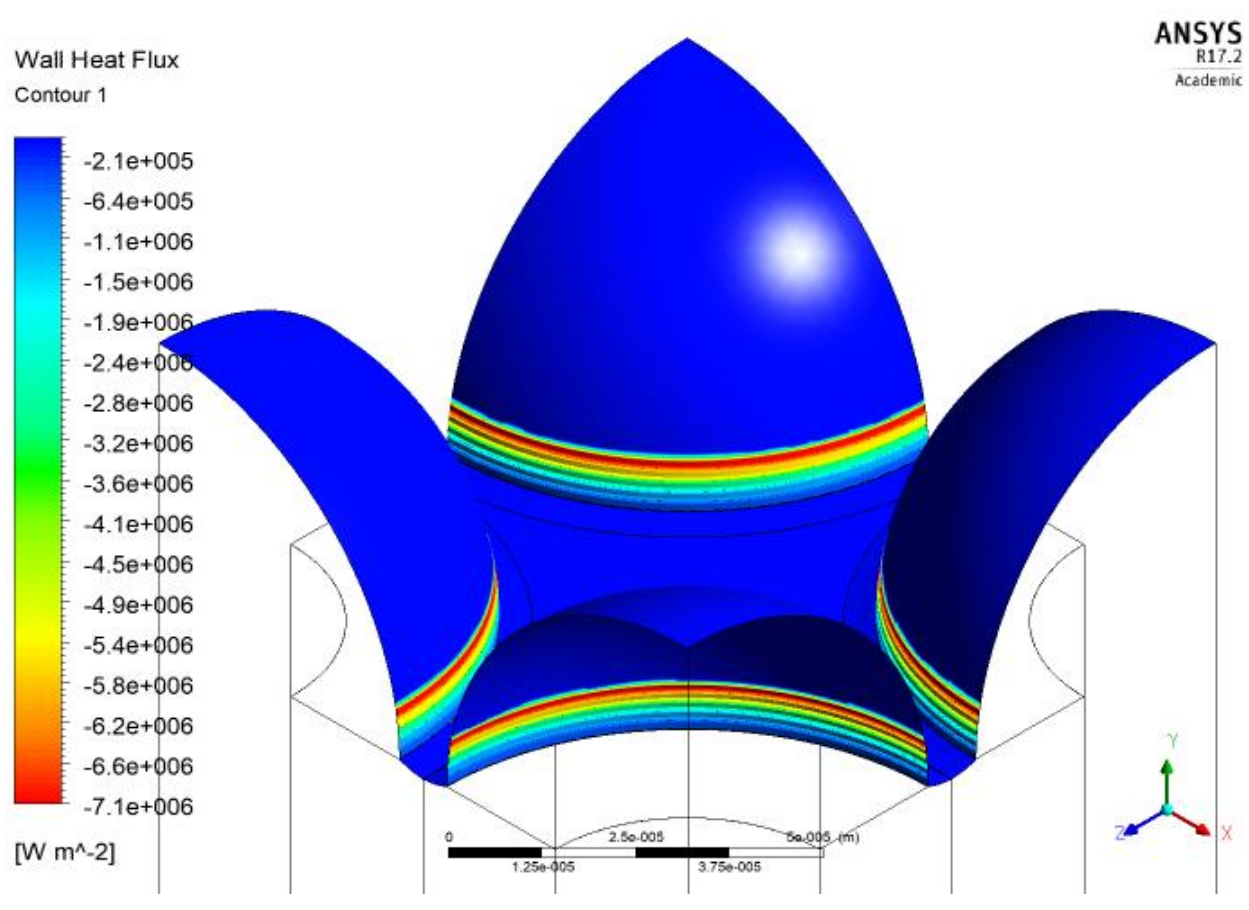

Figure 9 Representative heat flux distribution in the thin-film region

\subsection{Thermal characterization results}

Figure 10 shows the average substrate temperature and heat flux for $\mathrm{Cu}-\mathrm{CNT}$ micropillars as time progresses. The heat flux was increased by small increments to a maximum heat flux of $80 \mathrm{~W} / \mathrm{cm}^{2}$ and was subsequently decreased to zero by the same increments. For the range of heat flux tested, no noticeable hysteresis effect was observed. The maximum heat flux does not correspond to dryout or critical heat flux conditions. When the heat flux exceeded $80 \mathrm{~W} / \mathrm{cm}^{2}$, the electrical current through the heater increased to such a high level that resulted in the heater failure. Thus, the maximum heat flux shown is slightly below the heat flux at which the thin film heater failed. Each step on the plot represents situations where the power applied to the test module heater was incremented or reduced. The results show that the substrate temperature follows the same trend as the heat flux with some delay. A small temperature fluctuation was observed at a heat flux of 80 $\mathrm{W} / \mathrm{cm}^{2}$. This is likely due to bubble nucleation and transition to nucleate boiling at high heat fluxes, which may cause momentary disruption in the capillary induced flow. Figure 11 illustrates the difference between the substrate temperature and the saturation temperature inside the chamber $(\Delta \mathrm{T})$ for three different tests. To calculate the $\Delta \mathrm{T}$, the readings from all thermocouples were averaged. The measurements were repeated three times. As can be seen from this figure, a good repeatability was achieved over three measurements, as thermocouple readings for the three sets of measurements performed at each heat flux remained stable and differences were less than $5 \%$. The maximum temperature difference at a heat flux of $80 \mathrm{~W} / \mathrm{cm}^{2}$ was approximately $15.5{ }^{\circ} \mathrm{C}$, indicating a superior performance of the micropillar array. 
This is an Accepted Manuscript of an article published by Taylor \& Francis in Nanoscale and Microscale Thermophysical Engineering on 03 Oct 2019, available online: https://doi.org/10.1080/15567265.2019.1675830

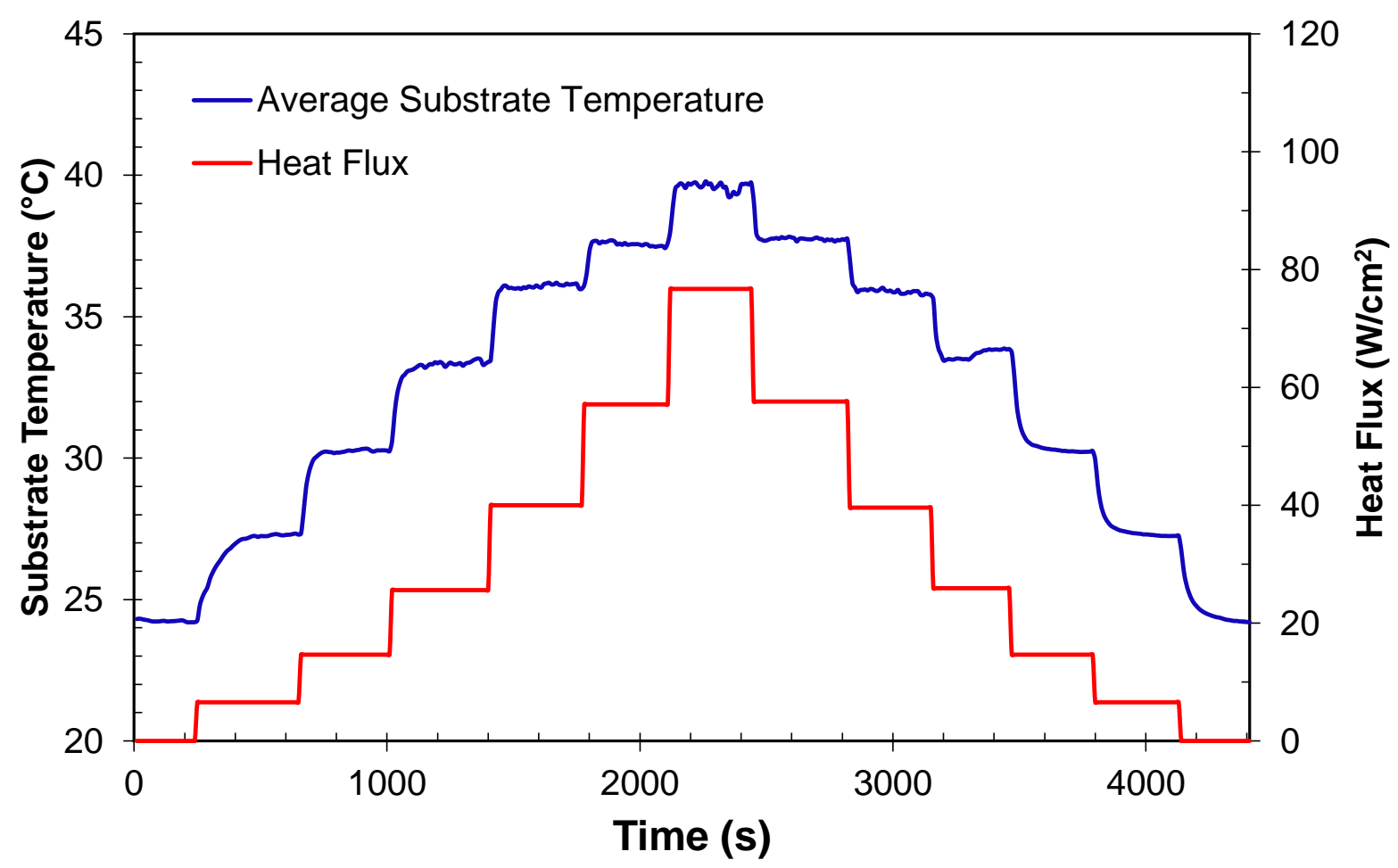

Figure 10 Variation of the average substrate temperature and heat flux as a function of time

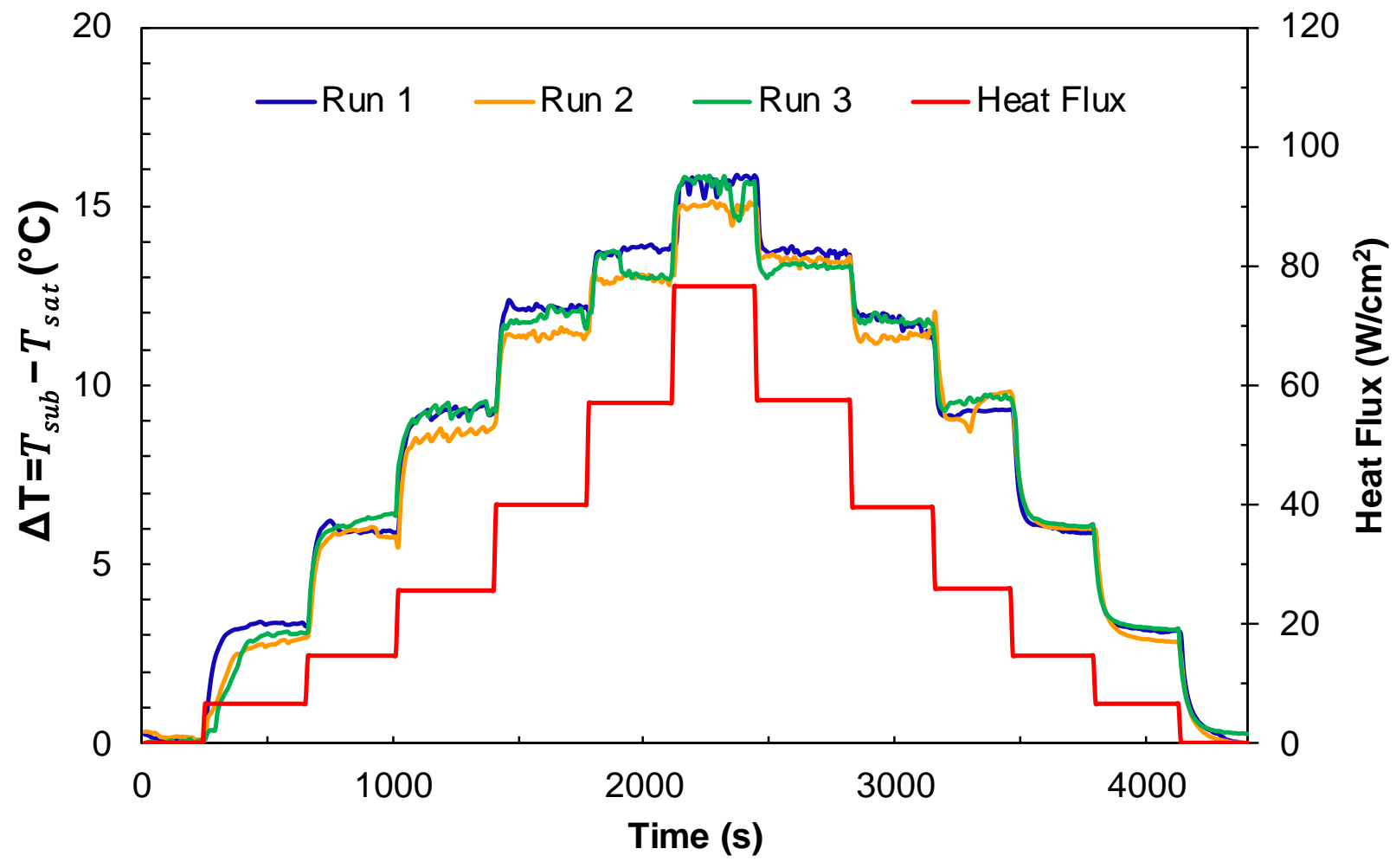


This is an Accepted Manuscript of an article published by Taylor \& Francis in Nanoscale and Microscale Thermophysical Engineering on 03 Oct 2019, available online: https://doi.org/10.1080/15567265.2019.1675830

Figure 11 Comparison of three different sets of $\Delta \mathbf{T}$ measurements at various heat fluxes indicating good repeatability

To compare the thermal performance of $\mathrm{Cu}-\mathrm{CNT}$ micropillars with copper micropillars, a copper micropillar array was fabricated and tested using the same test setup and procedures that were used for $\mathrm{Cu}-\mathrm{CNT}$ micropillars. The heat flux as a function of average wall superheat is shown in Fig. 12. The results clearly indicate that $\mathrm{Cu}-\mathrm{CNT}$ micropillars exhibit improved thermal performance compared to that of copper micropillars. The improvement in the thermal performance is more pronounced at higher heat fluxes. For example, at a wall superheat of $15^{\circ} \mathrm{C}$, the heat flux for the composite $\mathrm{Cu}-\mathrm{CNT}$ pillars is approximately $20 \%$ higher than that of copper micropillars. At a given wall superheat, a higher heat flux indicates a superior thermal performance for the $\mathrm{Cu}-\mathrm{CNT}$ micropillars. One reason for the improvement of thermal performance is a higher thermal conductivity of the $\mathrm{Cu}-\mathrm{CNT}$ micropillars. Additionally, the surface of composite $\mathrm{Cu}-\mathrm{CNT}$ micropillars were observed to have a higher number of pores per unit area than $\mathrm{Cu}$ micropillars, resulting in an increased thin-film area available for evaporation. The effective thermal conductivity of composite $\mathrm{Cu}-\mathrm{CNT}$ micropillars was estimated using an analytical model developed by Nan et al. [26]. Their model considers a random orientation of the CNT particles within the matrix and uses an effective medium approach. According to this model, the effective thermal conductivity of the composite structure can be found from:

$$
k_{e}=k_{m}\left(\frac{3+f\left(B_{x}+B_{z}\right)}{3-f B_{x}}\right)
$$

where

$$
\begin{gathered}
B_{x}=\frac{2\left[d\left(k_{c}-k_{m}\right)-2\left(R_{k} k_{c} k_{m}\right)\right]}{d\left(k_{c}-k_{m}\right)+2\left(R_{k} k_{c} k_{m}\right)} \\
B_{z}=\frac{L\left[\left(k_{c}-k_{m}\right)-2\left(R_{k} k_{c} k_{m}\right)\right]}{L k_{m}+2\left(R_{k} k_{c} k_{m}\right)}
\end{gathered}
$$

where $\mathrm{k}_{\mathrm{e}}, \mathrm{k}_{\mathrm{c}}$, and $\mathrm{k}_{\mathrm{m}}$ are the thermal conductivities of the composite, CNT, and matrix, respectively. $\mathrm{f}$ is the CNT volume fraction, $\mathrm{d}$ and $\mathrm{L}$ are the diameter and length of CNT, and $\mathrm{R}_{\mathrm{k}}$ is the thermal resistance. The average diameter and length of CNTs used in this study were $10 \mathrm{~nm}$ and $1-2 \mu \mathrm{m}$, respectively. The thermal conductivities of copper and CNT are approximately $385 \mathrm{~W} / \mathrm{m} . \mathrm{K}$ and $3,000 \mathrm{~W} / \mathrm{m} . \mathrm{K}$ [27], respectively. Using these values, the theoretical thermal conductivity of the composite copper-CNT micropillars was found to be $704.5 \mathrm{~W} / \mathrm{m} . \mathrm{K}$, which is nearly $80 \%$ higher than that of pure copper. However, when comparing the thermal performance of copper and $\mathrm{Cu}-$ CNT micropillars at a given wall superheat, smaller performance improvement is observed. This is due to the fact that the space between micropillars is filled with water and the thermal 
This is an Accepted Manuscript of an article published by Taylor \& Francis in Nanoscale and Microscale Thermophysical Engineering on 03 Oct 2019, available online: https://doi.org/10.1080/15567265.2019.1675830

conductivity of the liquid phase remains the same regardless of whether copper or $\mathrm{Cu}-\mathrm{CNT}$ micropillars are used.

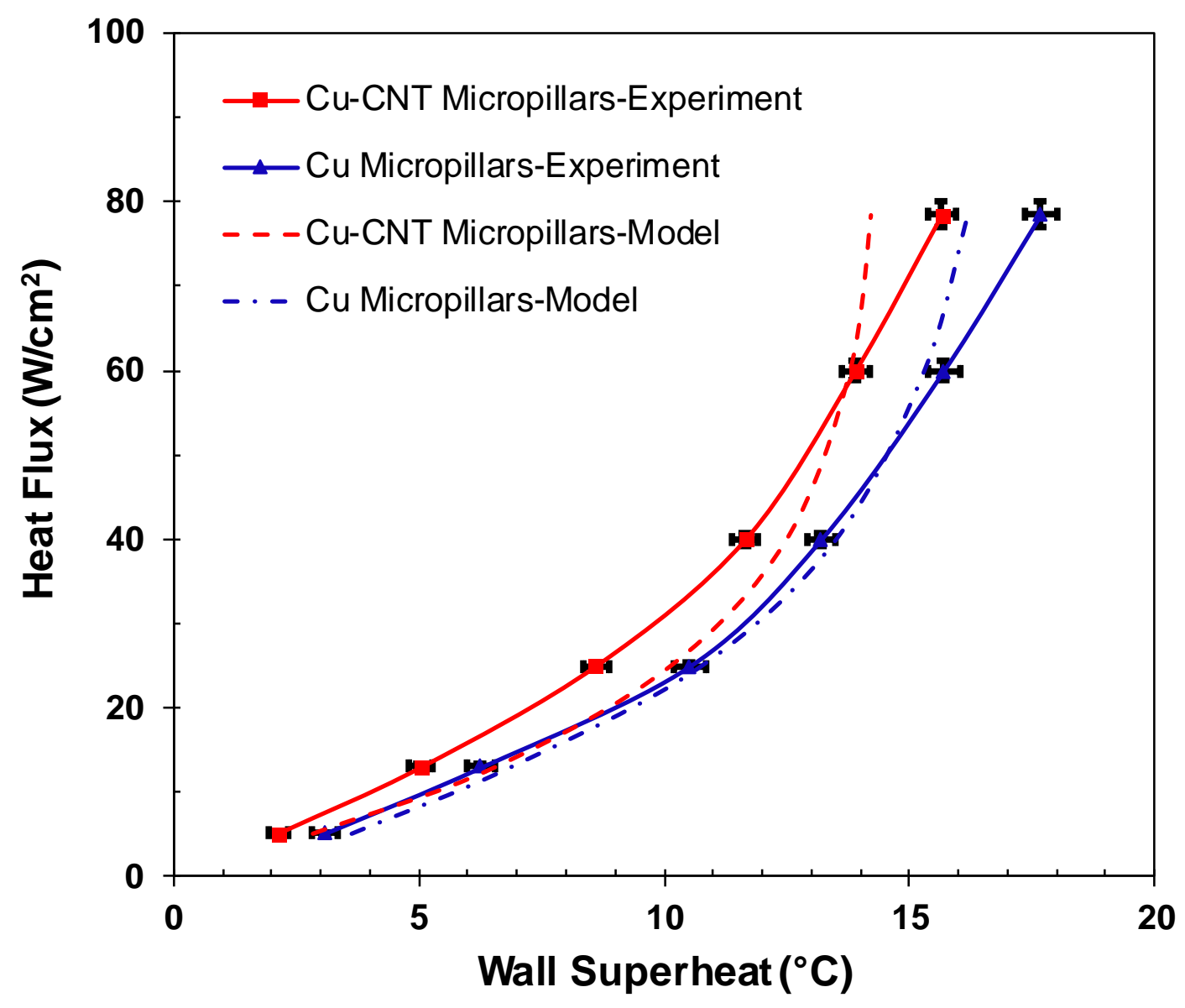

Figure 12 A comparison between the thermal performance of copper and $\mathrm{Cu}-\mathrm{CNT}$ micropillars

Figure 13 shows a comparison between the thermal resistance obtained from the experimental data (solid lines) and the results predicted by the thermal resistance model (dashed lines) for copper and $\mathrm{Cu}-\mathrm{CNT}$ micropillars. The results indicate that as the heat flux increases, the thermal resistance decreases. This trend is expected to reverse once dry-out conditions are established. However, for the range of heat fluxes tested in this study, no dry-out condition was observed. The decrease in thermal resistance with increasing heat flux can be explained by the fact that the film thickness in the thin-film region decreases as the heat flux increases. The modeling results showed that the interfacial resistance contributed most to the overall thermal resistance. The results also show that the overall thermal resistance of $\mathrm{Cu}-\mathrm{CNT}$ micropillars is approximately 5-10\% lower than that of copper micropillars depending on heat flux due to a higher thermal conductivity of $\mathrm{Cu}-\mathrm{CNT}$ micropillars which was estimated to be approximately $83 \%$ higher than copper $(\sim 385 \mathrm{~W} / \mathrm{m}$.K for copper vs. $\sim 705 \mathrm{~W} / \mathrm{m} . \mathrm{K}$ for $\mathrm{Cu}-\mathrm{CNT})$. As can be seen from this figure, both experimental data and modeling results behave very similarly and follow the same trend. The model predications are in good agreement with the experimental results, with errors within $\pm 8 \%$. This is likely due to several 
simplified assumptions made in the simulation, where the heat transfer coefficient in the thin-film region was prescribed based on a previously reported model and the meniscus curvature was assumed to be the same for all micropillars. Additionally, the micropillars were modeled as cylindrical pillars with semi-spherical structures on top. However, as discussed in section 2, the fabricated micropillars were approximately oval-shaped due to deformation of the polyester net under applied heat and pressure.

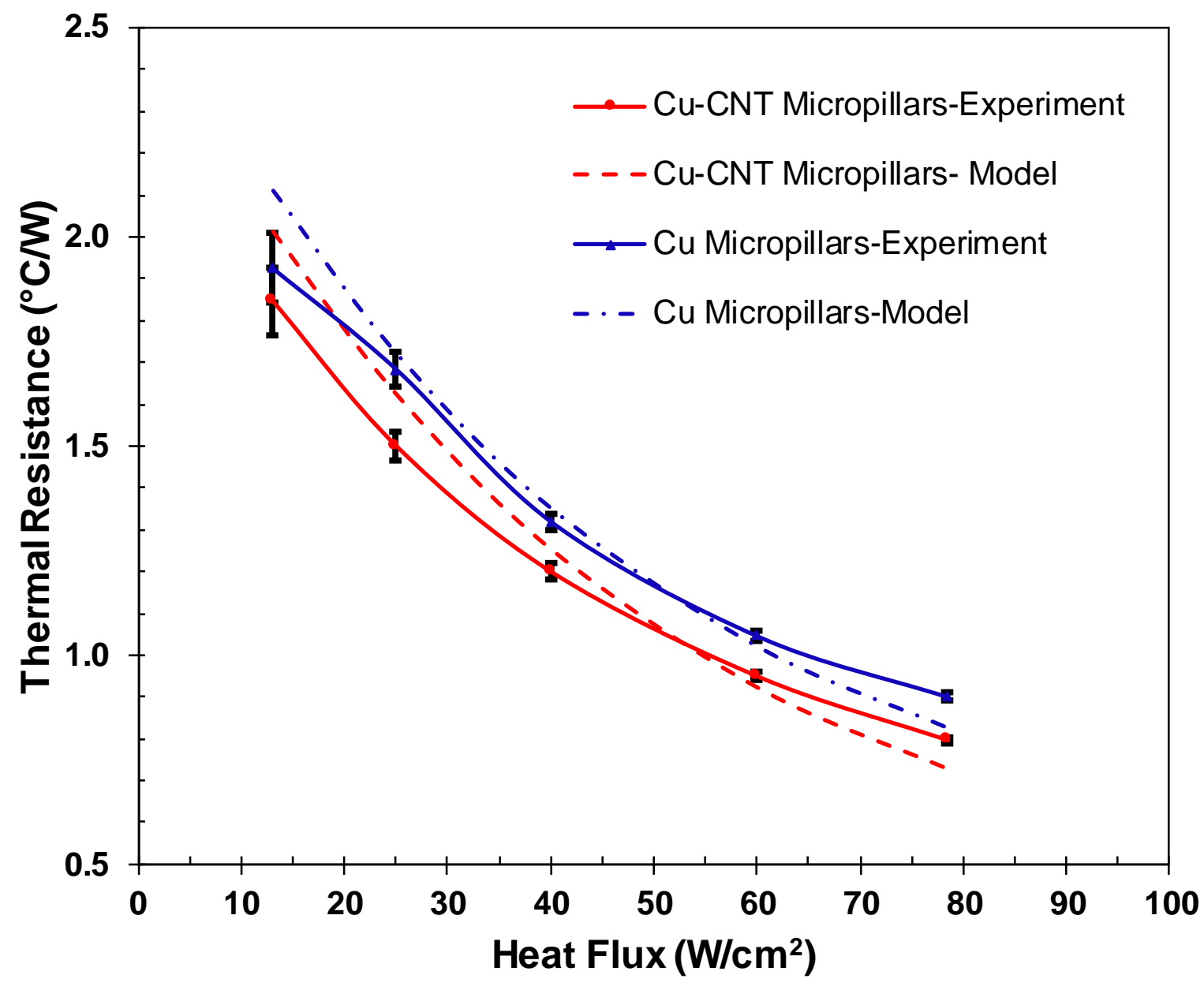

Figure 13 Comparison between experimental and simulated thermal resistance results. Note that at high heat fluxes, the error bars are too small to be visible.

\subsection{Corrosion characterization results}

The material and corrosion characterization study has been previously reported in detail in an earlier publication by the authors and it is not repeated here for brevity. The interested reader is referred to reference [28] for more detail. Briefly, corrosion resistance of the micropillars was studied using electrochemical impedance spectroscopy (EIS) in a $3.5 \mathrm{wt} . \% \mathrm{NaCl}$ solution at room temperature. For EIS measurements, a GAMRY Reference 3000 (Warminster, PA) with a threeelectrode setup was used. The specimen was used as a working electrode. The counter electrode 
This is an Accepted Manuscript of an article published by Taylor \& Francis in Nanoscale and Microscale Thermophysical Engineering on 03 Oct 2019, available online: https://doi.org/10.1080/15567265.2019.1675830

was a platinum electrode and the reference electrode was a saturated calomel electrode (SCE). Before performing the corrosion tests, the specimens were cleaned with acetone and rinsed with deionized water. The impedance spectra were obtained on each sample one hour after immersion, and recorded in the form of Nyquist plots. The results showed that the corrosion resistance of the $\mathrm{Cu}-\mathrm{CNT}$ micropillars was more than six-fold higher than that of copper micropillars, which can result in a long-term thermal durability of the wick structure. A significantly better corrosion resistance of $\mathrm{Cu}-\mathrm{CNT}$ composite micropillars can be attributed to several factors, including a low chemical reactivity of CNTs and a reduced metal structures on the surface of micropillars [29]. In addition, CNTs can enhance the corrosion resistance by filling microholes in the micropillar structures [30].

\section{Conclusions}

In this study, a novel method was developed to fabricate composite $\mathrm{Cu}-\mathrm{CNT}$ wick structures on a copper substrate for applications in capillary-driven phase-change cooling systems. A series of experiments were performed to quantify the thermal and corrosion performances of the fabricated wicks. Thermal characterization tests showed that this novel $\mathrm{Cu}-\mathrm{CNT}$ micropillar wick was able to dissipate approximately $80 \mathrm{~W} / \mathrm{cm}^{2}$ at a low superheat of $15^{\circ} \mathrm{C}$, making it a promising candidate for use in heat pipe and vapor chamber applications. Additionally, it was demonstrated that the thermal performance of $\mathrm{Cu}-\mathrm{CNT}$ micropillars was enhanced by up to $20 \%$ compared to those of the copper micropillars. Moreover, electrochemical impedance spectroscopy tests showed a sixfold improvement in corrosion resistance of $\mathrm{Cu}-\mathrm{CNT}$ micropillars. Adding CNTs to micropillar structure was found to significantly improve both the thermal and corrosion performance of the wick. Furthermore, a thermal resistance model was developed to predict the thermal performance of the mushroom-shaped micropillars. A good agreement between the model predictions and experimental data was obtained with a maximum discrepancy of less than $\pm 8 \%$.

\section{Acknowledgments}

This work was partially supported by a STEP grant from the SIUE Office of Research and Projects.

\section{References}

[1] G.P. Peterson, An Introduction to Heat Pipes: Modeling, Testing, and Applications, Wiley, New York, 1994.

[2] D. Reay, P. Kew, and R. Mcglen, Heat Pipes: Theory, Design and Applications: Sixth Edition. Heat Pipes: Theory, Design and Applications, Sixth Edition, Butterworth-Heinemann, 2013.

[3] J. Qua, H. Wub, P. Cheng, Q. Wang, and Q. Sun, Recent advances in MEMS-based micro heat pipes, International Journal of Heat and Mass Transfer, Vol. 110 pp. 294 -313, 2017.

[4] S. Dhanabal, M. Annamalai, and K. Muthusamy, Experimental investigation of thermal performance of metal foam wicked flat heat pipe, Experimental Thermal and Fluid Science, Vol. 82, pp. 482-492, 2017.

[5] W. Zhou, P. Xie, Y. Li, Y. Yan, and B. Li, Thermal performance of ultra-thin flattened heat pipes, Applied Thermal Engineering, Vol. 117 pp. 773 -781, 2017.

[6] J. L. Plawsky, A. G. Fedorov, S. V. Garimella, H. B. Ma, S. C. Maroo, L. Chen \& Y. Nam (2014) Nano- and Microstructures for Thin-Film Evaporation-A Review, Nanoscale and Microscale Thermophysical Engineering, 18:3, 251-269, DOI: $\underline{10.1080 / 15567265.2013 .878419 .}$. 
This is an Accepted Manuscript of an article published by Taylor \& Francis in Nanoscale and Microscale Thermophysical Engineering on 03 Oct 2019, available online: https://doi.org/10.1080/15567265.2019.1675830

[7] U. Vadakkan, G.M. Chrysler, J. Maveety, and M. Tirumala, A Novel Carbon Nano Tube Based Wick Structure for Heat Pipes/Vapor Chambers, Twenty-third Annual IEEE Semiconductor Thermal Measurement and Management Symposium, 18-22 March 2007. San Jose, CA.

[8] S. Ujereh, T. Fisher, and I. Mudawar, Effects of Carbon Nanotubes Arrays on Nucleate Pool Boiling, International Journal of Heat and Mass Transfer, Vol. 50, pp. 4023-4038, 2007.

[9] J.J. Zhou, F. Noca, and M. Gharib, Flow Conveying and Diagnosis with Carbon Nanotube Arrays, Nanotechnology, Vol. 17, pp. 4845-4853, 2006.

[10] Q. Cai, C.L. Chen, (2010), Design and Test of Carbon Nanotube Biwick Structure for HighHeat-Flux Phase Change Heat Transfer. Journal of Heat Transfer. 132. 052403. 10.1115/1.4000469.

[11] J.A. Weibel, S.S. Kim, T.S. Fisher \& S.V. Garimella (2012) Carbon Nanotube Coatings for Enhanced Capillary-Fed Boiling from Porous Microstructures, Nanoscale and Microscale Thermophysical Engineering, 16:1, 1-17, DOI: 10.1080/15567265.2011.646000

[12] Y. Nam, S. Sharratt, C. Byon, S.J. Kim, and Y.S. Ju, Fabrication and Characterization of the Capillary Performance of Superhydrophilic $\mathrm{Cu}$ Micropost Arrays, Journal of Microelectromechanical Systems, 19, pp. 581-588, 2010.

[13] C. Ding, G. Soni, P. Bozorgi, B. D. Piorek, C. D. Meinhart, and N. C. MacDonald, A Flat Heat Pipe Architecture Based on Nanostructured Titania, J. Microelectromech. Syst., 19, pp. 878-884, 2010.

[14] H-C. Chiu, R-H. Hsieh, K. Wang, J-H. Jang, and C-R. Yu, The heat transfer characteristics of liquid cooling heat sink with micro pin fins, International Communications in Heat and Mass Transfer, Vol. 86, pp. 174-180, 2017.

[15] R. Ranjan, S.V. Garimella, J. Y. Murthy \& K. Yazawa (2011) Assessment of Nanostructured Capillary Wicks for Passive Two-Phase Heat Transport, Nanoscale and Microscale Thermophysical Engineering, 15:3, 179-194, DOI: 10.1080/15567265.2011.597492.

[16] R. Ranjan, J.Y. Murthy, and S.V. Garimella, Analysis of the Wicking and Thin-Film Evaporation Characteristics of Microstructures, Journal of Heat Transfer, Vol. 131, pp. 1-11, 2009.

[17] R. Ranjan, A. Patel, S.V. Garimella, and J. Y. Murthy, Wicking and thermal characteristics of micropillared structures for use in passive heat spreaders, International Journal of Heat and Mass Transfer, Vol. 55, pp. 586-596, 2012.

[18] J.A. Weibel, S.V. Garimella, J. Y. Murthy, and D.H. Altman, Design of Integrated Nanostructured Wicks for High-Performance Vapor Chambers, IEEE Transaction on Components, Packaging and manufacturing technology, Vol. 1, No. 6, pp. 859-867, 2011.

[19] S. Adera, D. Antao, R. Raj, and E.N. Wang, Design of micropillar wicks for thin-film evaporation, International Journal of Heat and Mass Transfer, Vol. 101, pp. 280-294, 2016.

[20] Y. Zhu, D.S. Antao, Z. Lu, S. Somasundaram, T. Zhang, and E.N. Wang, Prediction and Characterization of Dry-out Heat Flux in Micropillar Wick Structures, Langmuir, Vol. 32, pp. 1920-1927, 2016.

[21] D. F. Hanks, Z. Lu, J. Sircar, T. R. Salamon, D. S. Antao, K. R. Bagnall, B. Barabadi \& E.N. Wang (2018) Nanoporous membrane device for ultra high heat flux thermal management, Microsystems \& Nanoengineering, 4:1, DOI: 10.1038/s41378-018-0004-7.

[22] H. Wu, G. Ding, Y. Wang, Y. Cao, H. Wang, and C. Yang, Composite Electrodeposition of Zinc and Carbon Nanotubes, IEEE Review On Advances in Micro/Nano and Molecular Systems, Vol. 1, 211-212, 2006. 
[23] S.J. Kline and F.A. McClintock, Describing Uncertainties in Single Sample Experiment, Mechanical Engineering, Vol. 75., pp. 3-9, 1953.

[24] K. Park, K-J. Noh, and K-S. Lee, Transport phenomena in the thin-film region of a microchannel, International Journal of Heat and Mass Transfer, Vol. 46, pp. 2381-2388, 2003.

[25] K. Park, K-J. Noh, K-S. Lee, Evaporative Modeling in a Thin-Film Region of Micro-Channel, International Refrigeration and Air Conditioning Conference, West Lafayette, Indiana, USA, Paper 576, 2002.

[26] C.W. Nan, Z. Shi, and Y. Lin, A simple model for thermal conductivity of carbon nanotubebased composites, Chemical Physics Letters, 375, pp.666-9, 2003.

[27] S. Shenogin, A. Bodapati, L. Xue, R. Ozisik, and P. Keblinski, Effect of chemical functionalization on thermal transport of carbon nanotube composites, Applied Physics Letters, 85 pp.2229-31, 2004.

[28] S. Ghanbari and J. Darabi, Fabrication and Material Characterization of Copper and CopperCNT Micropillars, Mater. Res. Express 2, 075501, 2015.

[29] K. Krishnaveni, S. Narayanan, and S.K. Seshadri, Corrosion resistance of electrodeposited Ni-B and Ni-B-Si3N4 composite coatings, Journal of Alloys and Compounds, 480. pp.765770, 2009.

[30] Q. Li, X. Yang, L. Zhang, J. Wang, and C. Bo, Corrosion resistance and mechanical properties of pulse electrodeposited $\mathrm{Ni}-\mathrm{TiO} 2$ composite coating for sintered $\mathrm{NdFeB}$ magnet, Journal of Alloys and Compounds, 482 pp.339-344, 2009. 